\title{
Protection against anaphylactic shock by gadolinium chloride- induced Kupffer cell blockade
}

\author{
George Lázár ${ }^{\mathrm{a}, *}$, George Lázár, Jr. ${ }^{\mathrm{b}}$, Joseph Kaszaki ${ }^{\mathrm{c}}$, Judit Oláh ${ }^{\mathrm{d}}$, \\ Elizabeth Husztik ${ }^{\text {a }}$ \\ a Institute of Pathophysiology, ' Department of Surgery, 'Institute of Experimental Surgery, 'Department of Dermatology, \\ Albert Szent-Györgyi Medical University, 6701 Szeged, PO Box 531, Hungary
}

\begin{abstract}
Data in the literature concerning the role of Kupffer cells in anaphylaxis are contradictory. In the present study the effect of Kupffer cell blockade induced by gadolinium chloride $\left(\mathrm{GdCl}_{3}\right)$ on anaphylactic shock was investigated. Our observations show that $\mathrm{GdCl}_{3}$ prevents lethal anaphylactic shock in mice sensitized to ovalbumin. Gadolinium chloride given i.v. in a dose of $1 \mathrm{mg}(100 \mathrm{~g})^{-1}$ body weight 24 or $48 \mathrm{~h}$ before the elicitation of anaphylactic shock resulted in $80 \%$ survival, compared with the $43 \%$ survival in the control group. The same dose of gadolinium chlorde and also other rare earth metal salts, like lanthanum-, praseodymium-, neodymium-, and european chlorides given i.v., one day before the elicitation of anaphylactic shock, greatly reduced the mortality in mice sensitized with ovalbumin and Bordatella pertussis vaccine. However, gadolinium chloride given, per os, in a dose of $2 \mathrm{mg}(100 \mathrm{~g})^{-1}$ body weight, one or two days before the elicitation of anaphylactic shock were ineffective. Gadolinum chloride similarly abrogated the symptoms of anaphylaxis, including the accumulation of serotonin and histamine in the liver. The results suggest that Kupffer cells play an important role in mouse anaphylaxis.
\end{abstract}

Keywords: Gadolinium chloride; Kupffer cell; Kupffer cell blockade; Anaphyalaxis; f-Elements

\section{Introduction}

In studies of the physiological and pathophysiological roles of the reticuloendothelial system (RES), the depression or blockade of the granulopectic activity has attracted considerable attention. Among substances effectively depressing the reticuloendothelial activity are materials with different physicochemical properties, for example various colloids [1], steroids such as cortisone [2], esters of fatty acids, such as methyl palmitate [3], dextran sulphate [4], silica [5] and carrageenan [6]. Our earlier experiments [7,8] demonmstrate that rare earth metal salts, among them gadolinium chloride, depress the reticuloendothelial activity and inhibit or completely abolish the effects of some reticuloendothelial stimulants. Our light- and electronmicroscopic investigations indicate that, as a results of the action of gadolinium chloride, the impaired Kupffer cell phagocytosis is due to the defects in surface attachment and in the engulfment phase of phagocytosis.

\footnotetext{
${ }^{*}$ Corresponding author.
}

A number of data suggest that macrophages have important functions as accessory and regulatory cells in the induction and expression of immune responses.

Kupffer cells, the resident macrophages of the liver, have been shown to express class II antigens of the major histocompatibility complex and to have the capacities for antigen uptake and presentation in vitro, but their regulatory roles in the induction and expression of the immune response have not been well defined. In the present studies we investigated the effects of blockade of Kupffer cell phagocytosis by rare earth salts on the course of mouse anaphylaxis and the accumulation of anaphylactic mediators (histamine and serotonin) in the liver.

\section{Materials and methods}

Male CFLP mice (Animal House, Gödöllö Hungary) weighing 27-30 g were injected i.p. with $100 \mu \mathrm{g}$ ovalbumin (Koch-Licht, England) precipitated with aluminium hydroxide. In some of the experiments Bordetella pertussis vaccine $\left(10^{10}\right.$ organisms/animal $)$ 
(Human Institute for Serological Production and Research, Budapest) was used to augment sensitization. The animals were challenged i.v. 12 days after sensitization with $100 \mu \mathrm{g}$ of the same antigen in $0.2 \mathrm{ml}$ of physiological saline. The survival rate was recorded over the next $24 \mathrm{~h}$.

Serotonin was measured by the spectrofluorimetric method of Shellenberger and Gordon [9] and histamine by means of the radioenzymatic method of Beaven and Horakova [10]. Histamine $\mathrm{N}$-methyltransferase was purified from rat kidney.

Kupffer cell phagocytosis blockade was induced by the method published earlier [7,8]. Rare earth metal chlorides (K. and K. Laboratory, Plainview, New York) was dissolved in physiological saline and injected i.v. in a dose given in the text.

In some of the experiments gadolinium chloride was administered by stomach tube in $0.5 \mathrm{ml}$ physiological saline in a dose given in the text.

Results were evaluated biometrically with the Student $t$ test, and the chi square test. Analysis of variance and multiple comparisons were performed by the Scheffé procedure.

\section{Results}

Our observations show that gadolinium chloride prevents the lethal anaphylactic shock of mice sensitized to ovalbumin. Gadolinium chloride given in an i.v. dose of $1 \mathrm{mg}(100 \mathrm{~g})^{-1}$ body weight 24 or $48 \mathrm{~h}$ before the elicitation of anaphylactic shock resulted in $90 \%$ survival, compared to the $43 \%$ survival in the control group injected only with ovalbumin on the 12 th day of the experiment. The same dose of gadolinium chloride given 4 or 6 days before the challenge of anaphylaxis also protected mice against lethal anaphylactic shock $(80 \%$ survival) (Fig. 1).

Mice sensitized with ovalbumin containing Bordetella pertussis vaccine exhibited much more severe anaphylaxis (10\% survival), but they too were protected by $\mathrm{GdCl}_{3}$ pretreatment (80\% survival) (Fig. 2). Fig. 2 shows that the chlorides of lanthanum, praseodymium, neodymium, gadolinium, holmium, erbium given in an i.v. dose of $1 \mathrm{mg}(100 \mathrm{~g})^{-1}$ body weight one day before the elicitation of anaphylactic shock resulted in $70-100 \%$ survival, compared to the $10 \%$ survival in the control group injected only with ovalbumin on the 12 th day of the experiment.

The effectiveness of gadolinium chloride to protect mice against anaphylactic mortality was dependent on the route of administration of the rare earth metal salt. Fig. 3 shows that gadolinium chloride administered orally in a dose of $4 \mathrm{mg}(100 \mathrm{~g})^{-1}$ body weight $24 \mathrm{~h}$, or in a dose of $2 \mathrm{mg}(100 \mathrm{~g})^{-1}$ body weight 24 or 48 $h$ before the elicitation of anaphylactic shock, did not exert protection against anaphylactic mortality.

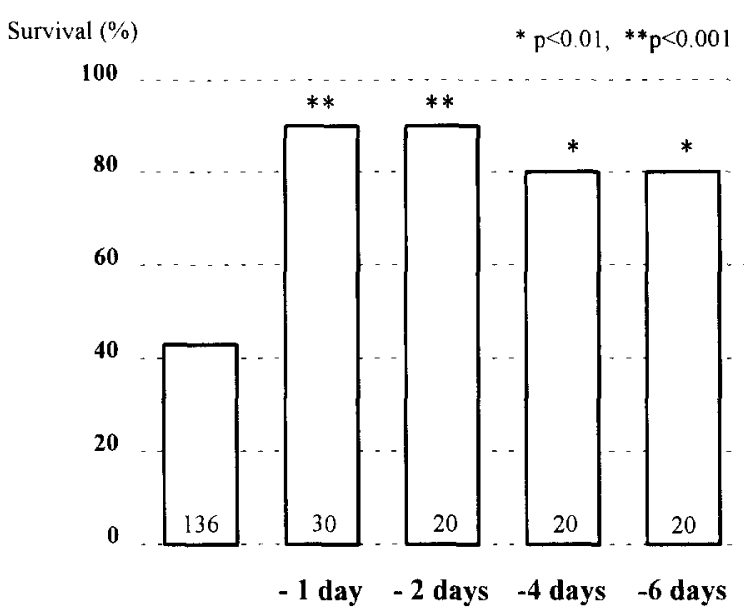

Fig. 1. Effect of gadolinium chloride on the survival rate in anaphylactic shock. Mice were sensitized i.p. with $100 \mu \mathrm{g}$ ovalbumin precipitated with aluminum hydroxide. Gadolinium chloride was injected i.v. in a dose of $1 \mathrm{mg}(100 \mathrm{~g})^{-1}$ body weight, before the challenge of anaphylaxis, on the day indicated in the figure. The numbers in the columns are the number of animals per group.

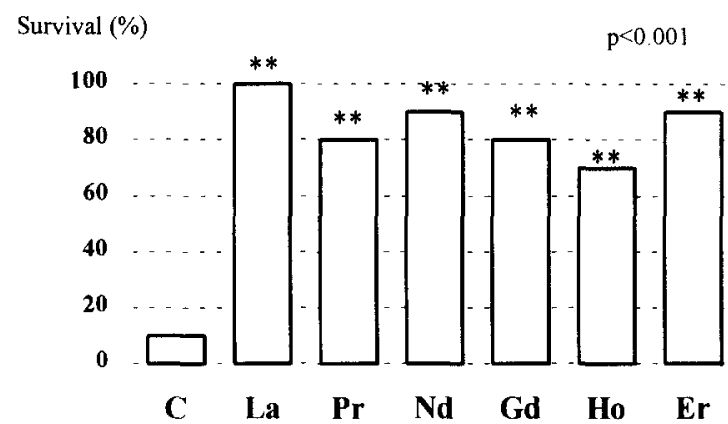

Fig. 2. Effect of rare earth metal chlorides on the survival rate in anaphylactic shock. Mice were sensitized i.p. with $100 \mu \mathrm{g}$ ovalbumin containing Bordetella pertussis vaccine $\left(10^{10}\right.$ organisms $)$ and precipitated with aluminium hydroxide. Lanthanum (La), Praseodymium (Pr), Neodymium (Nd), Gadolinium (Gd), Holmium (Ho), Erbium (Er) chloride were administered i.v. at at he dose level of $1 \mathrm{mg}$ $(100 \mathrm{~g})^{-2}$ body weight, one day before challenge of anaphylaxis.

Gadolinium chloride pretreatment also greatly reduces the symptoms of anaphylaxis, including the accumulation of histamine and serotonin in the liver. Fig. 4 shows that the elicitation of anaphylactic shock leads to the accumulation of histamine and serotonin in the liver, but it is prevented by gadolinium chloride pretreatment (Fig. 4).

\section{Discussion}

Rare earth metals have diverse biological and pharmacological effects $[11,12]$. Many of these can be explained by the replacement of calcium ion, or the inhibition of its movement across the cell membrane by these elements $[8,13]$. Since the crystal radii of the rare earth metal ions are very similar to that of calcium 
Survival $(\%)$

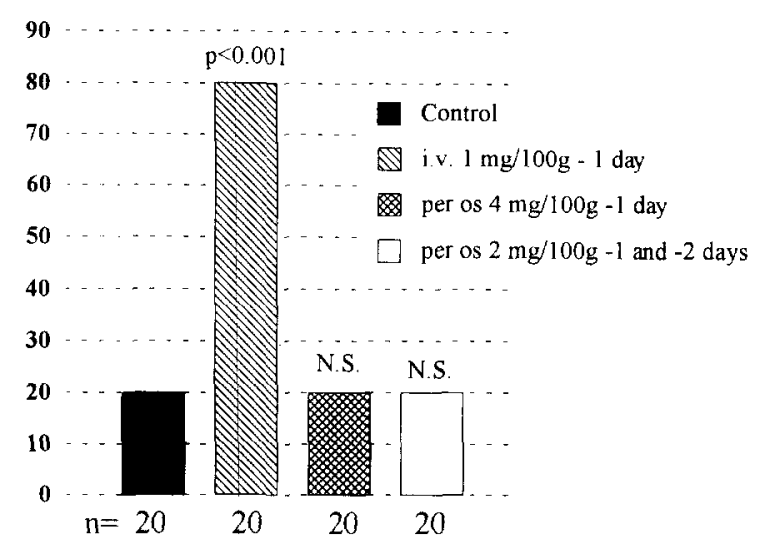

Fig. 3. Effect of gadolinium chloride given intravenously or orally on the survival rate of anaphylactic shock. Mice were sensitized i.p. with $100 \mu \mathrm{g}$ ovalbumin containing Bordetella pertussis vaccine $\left(10^{10}\right.$ organisms) and precipitated with aluminium hydroxide. Gadolinium chloride was injected i.v. in a dose of $1 \mathrm{mg}(100 \mathrm{~g})^{-1}$ body weight, one day before the challenge of anaphylaxis or was administered orally in a dose of $2 \mathrm{mg}(100 \mathrm{~g})^{-1}$ body weight one or two days before the challenge of anaphylaxis.

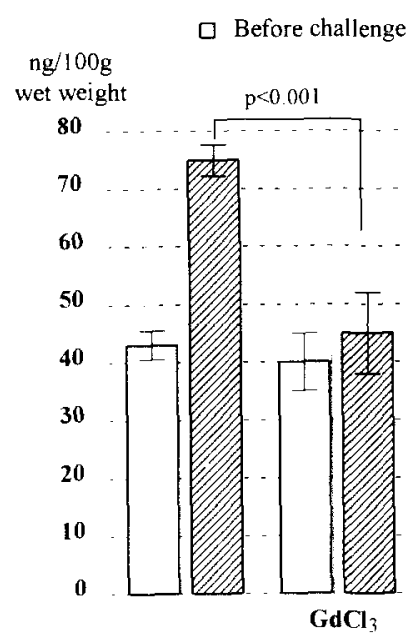

Serotonin

\section{b $1 \mathrm{~h}$ after challenge}

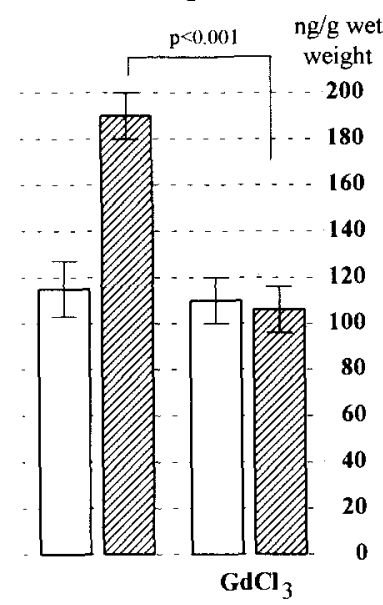

Histamine
Fig. 4. Effect of gadolinium chloride on the accumulation of serotonin and histamine in the ljver in anaphylactic shock. Both serotonin and histamine were determined before and $1 \mathrm{~h}$ after the challenge of anaphylactic shock. Mice were sensitized ip with $100 \mu \mathrm{g}$ ovalbumin and Bordetella pertussis vaccine $\left(10^{10}\right.$ organisms) precipitated with aluminum hydroxide. Gadolinium chloride was injected in a dose of $1 \mathrm{mg}(100 \mathrm{~g})^{-1}$ body weight, i.v., 1 day before the challenge of anaphylaxis.

ion and because of their higher valency, they can displace and replace calcium ions in biological systems, as well as prevent the uptake of calcium ions at various cellular sites. Results obtained with chlorides of lanthanum, praseodymium, neodymium, gadolinium, holmium and erbium, suggest that therere is no marked difference in potency, at least in the inhibitory effect on mouse anaphylaxis, between the various lanthanides. Pearce and White [14] found that ions of lanthanide series (lanthanum, praseodymium, neodymium, dysprosium and lutetium) inhibit histamine release from mast cells by allergen and anti-IgE but in the effect there is no obvious dependence on ionic radius. However, the histamine release induced by concanavalin A was weakly antagonized by lanthanum but strongly inhibited by higher lanthanides.

Among the biological effects, the rare earth metal ions markedly affect the functions of cells involved in inflammation and immunological phenomena [15]. The anti-inflammatory activity of lanthanides was explained by their anticoagulant activity [16]. Earlier, we have recognised that different rare earth metals injected intravenously depress the reticuloendothelial activity and inhibit or completely abolish the RES-stimulating effect of zymosan, triolein and Bacillus Callmette Guérin (BCG) [7]. On the other hand, as to in vitro studies it has been observed that lanthanides inhibit chemotaxis of polymorphonuclear leukocytes [17], the antigen-induced histamine release from mast cells [14], and the proliferative response of human lymphocytes to various mitogens and to "purified protein derivative" (PPD) of tuberculin antigen [15]. According to our recent studies, the Kupffer cell blockade induced by gadolinium chloride inhibits the hypotension induced by immune globulin aggregates [18], which may be involved in the mechanisms of the protective effect of Kupffer cell phagocytosis blockade on mouse anaphylaxis, since during anaphylactic response, sensitized mast cells release chemical mediators such as histamine in resposne to allergen and these released mediators induce vasodilatation and severe hypotension [19].

Macrophages, besides mast cells and basophils, have special membrane receptors for anaphylactic antibodies [20], and the interaction between these membranebound antibodies and the specific antigen leads to activation of macrophages, and to release of mediators of anaphylaxis [21]. This is supported by the present findings, that the elicitation of anaphylactic shock leads to accumulation of serotonin and histamine in the liver, which are important mediators in mouse anaphylaxis [22].

It is suggested in the literature [23] that in severe injuries, such as shock states, the gradual activation of liver macrophages and the excessive release of macrophage destructive and immunosuppressive products may contribute to the development of "multiple organ failure". This is supported by our earlier investigations [24], that Kupffer cell phagocytosis blockade induced by gadolinium chloride improves the survival rate in septic peritonitis and septic shock induced in rats by coecal ligation and puncture. The observation in the present studies that the blockade of Kupffer cells with gadolinium chloride prevents lethal anaphylactic shock suggests that Kupffer cells may play an important role in anaphylaxis. 
Earlier we have found [25] that gadolinium chloride causes a shift in liposome uptake within the Kupffer cell population from the phagocytically most active cell fraction, containing predominantly large cells, to the cells of much smaller size, which are normally only slightly active. A recent study has shown [26], that gadolinium chloride selectively eliminates the large liver macrophages situated in the periportal zone of the liver acinus. The observations that the Kupfer cell phagocytosis blockade with gadolinium chloride greatly reduced the mortality rates and the symptoms of mouse anaphylaxis, including the accumulation of serotonin and histamine in the liver, suggest that the activation of Kupffer cells may contribute to the development of anaphyalctic shock and this is due first of all to the impairment of the function of the normally most active Kupffer cell populations.

\section{Acknowledgements}

This work was supported by the Hungarian National Science Foundation (OTKA, grant No. 2684, E 012054, $T$ 012963) and Hungarian Health Science Foundation (ETT T-10 607/1993).

\section{References}

[1] N. Jancsó, Speicherung, Akadémiai Kiadó, Budapest, 1955.

[2] D.L.J. Bilbey and T. Nicol, Nature, 182 (1958) 674.

[3] N.R. Di Luzio and W.R. Wooles, Am. J. Physiol., 206 (1964) 939.
[4] J.W.B. Bradfield, Br. J. Exp. Path., 61 (1980) 617.

[5] A.C. Allison, J.S. Harrington and M. Birback, J. Exp. Med., 124 (1966) 141.

[6] P.J. Catansaro, H.J. Schwartz and R.C. Graham, Am. J. Path., 64 (1971) 387.

[7] G. Lázár, J. Reticuloendothel. Soc. 13 (1973) 231.

[8] E. Husztik, G. Lázár and Á Párducz, Brit. J. Exp. Pathol., 61 (1980) 624.

[9] M.K. Shellenberger and J.H. Gordon, Anal. Biochem., 39 (1971) 356.

[10] M.A. Beaven and Z. Horakova, in M. Roche e Silva (ed.), Handbook of Experimental Pharmacology, Vol. 18, SpringerVerlag, Berlin, 1978.

[11] C.H. Evans, in P. F. Baker (ed.), Handbook of Experimental Pharmacology Vol. 83, Springer-Verlag, Berlin/Heidelberg, 1988, p. 527.

[12] T.J. Haley, J. Pharm. Sci., 54 (1965) 663.

[13] G.B. Weiss and F.F. Goodman, J. Pharmacol. Exp. Ther., 169 (1969) 46.

[14] F.L. Pearce and J.R. White, Br. J. Pharmacol., 72 (1981) 341.

[15] M. Yamaga and C.H. Evans, Experientia, 45 (1989) 1129.

[16] N. Jancsó, J. Pharm. Pharmac., 13 (1961) 577.

[17] M.M. Boucek and R. Synderman, Science, 193 (1979) 905.

[18] B. Jenei, G. Lázár, K. Bartha and G.A. Medgyesi, Agents and Actions, 32 (1992) 333.

[19] S. Osada, H. Ichiki, H. Oku, K. Ishiguro, M. Kunitotmo and M. Semma, Eur. J. Pharmacol., 252 (1994) 347.

[20] S.J. Lane, A.R. Sousa and T.H. Lee, Allergy, 49 (1994) 201.

[21] M. Joseph, J.P. Dessaint and J.P. Capron, Cell. Immunol, 34 (1977) 247.

[22] S. Kaneta, H. Kanbara, E. Fujihira and M. Mitsuya, Int. Archs Allergy Appl. Immun., 80 (1986) 333.

[23] J.R. Border, Arch. Surg., 123 (1988) 285.

[24] G. Lázár, Jr., E. Husztik and G. Lázár, in G. Schlag and H. Redl, First Vienna Shock Forum, Part B.: Monitoring and Treatment of Shock Alan R. Liss, New York, 1987, p. 323.

[25] G. Lázár, M. van Galen and G.L. Scherphof, Biochim. Biophys. Acta, 1011 (1989) 97.

[26] M.J. Hardonk, F.W.J. Dijkhuis, C.E. Hulstaert and J. Koudstaal, J. Leukocyte Biol., 52 (1992) 296. 